\title{
Improving Type 2 Diabetes Management in General Practice Using a Second-Generation Basal Insulin Analogue Insulin Glargine $300 \mathrm{U} / \mathrm{mL}$ : A Practical Guide
}

\author{
Gary Deed (1) - Roy Rasalam • Chee Khoo - Tom Dover •
}

Nick Forgione

Received: September 2, 2019 / Published online: October 21, 2019

(C) The Author(s) 2019

\section{ABSTRACT}

Type 2 diabetes management can be improved by the use of second-generation basal insulin analogues as the first choice on commencement of insulin, in this instance focussing on insulin glargine $300 \mathrm{U} / \mathrm{mL}$ (Gla-300). The clinical application of the use of Gla-300 include advantages such as less intra- and interpatient variability in glucose control resulting in rather less hypoglycaemia, longer duration of action and greater flexibility in the timing of administration thus suiting a wide range of patient presentations.

Funding: Sanofi Australia.

Enhanced Digital Features To view enhanced digital features for this article go to https://doi.org/10.6084/ m9.figshare.9892166.

G. Deed $(\bowtie)$

Mediwell Medical Clinic, Brisbane, QLD, Australia

e-mail: drgarydeed@outlook.com

R. Rasalam

James Cook University, Townsville, QLD, Australia

C. Khoo

Western Sydney University, Sydney, NSW, Australia

T. Dover

Ipswich Hospital, Brisbane, QLD, Australia

N. Forgione

Trigg Health Care Centre, Perth, WA, Australia
Keywords: Case vignettes; Practical guide; Second-generation insulin analogues; Type 2 diabetes

\section{WHEN SHOULD I CONSIDER INITIATING INSULIN?}

As the worldwide prevalence of type 2 diabetes increases (8.8\% of the adult population) [1], general practice has become the principal point of care for the majority of these patients. Type 2 diabetes is a progressive disease associated with multiple long-term complications [2], mostly directly related to glycaemic control as measured by glycated haemoglobin A1c (HbA1c). While the recent advent of newer therapies has resulted in wider choice of treatments, insulin remains the most effective way of lowering blood glucose. In most clinical scenarios it is introduced when other therapies are unable to effectively reduce glucose levels to achieve individualised HbA1c targets. However, there is evidence that there still exists considerable clinical inertia around introducing insulin. Studies in Australia and internationally have shown that insulin was often initiated after HbA1c levels had remained between $8 \%$ and $9.3 \%$ for an extended period of time [3-5], thereby increasing the risk of diabetes complications. Barriers that underlie this include practitioner and patient fear of hypoglycaemia and the complexity of initiation [6]. As general 
practice is the main point of care for these patients, it is essential that healthcare providers become familiar with the use of insulin and are comfortable with its initiation. The newer second-generation insulin analogues provide an excellent option with a simple initiation regimen and a reduced risk of hypoglycaemia.

Insulin initiation may be useful in the following clinical scenarios:

1. Metabolic decompensation-hyperglycaemia with polyuria, polydipsia, weight loss.

2. Maximally tolerated non-insulin agents without achievement of glycaemic targets.

When insulin therapy is initiated and titrated, it is important to make the correct choice to minimise impact on patients. Choosing an insulin that promotes simpler regimens, less hypoglycaemia and prolonged daily activity with less variability will allow flexibility for modern lifestyles and dietary patterns. Newer second-generation basal insulin analogues with changes in pharmacodynamics can assist the clinicians to support glycaemic management focussing on patient needs.

To address these issues, the authors have reviewed the evidence that second-generation insulin analogue options can assist in improving outcomes supported by clinical guidelines.

\section{COMPLIANCE WITH ETHICS GUIDELINES}

This article is based on previously conducted studies and does not contain any studies with human participants or animals performed by any of the authors.

\section{WHY SHOULD I CHOOSE A SECOND-GENERATION INSULIN ANALOGUE?}

\section{Pharmacology}

Second-generation basal insulin analogues insulin glargine $300 \mathrm{U} / \mathrm{mL}$ (Toujeo ${ }^{\circledR}$ ) and insulin degludec (Tresiba ${ }^{\circledR}$ ) have been developed to address clinical needs for a stable predictable basal insulin response beyond $24 \mathrm{~h}$. These insulin analogues are characterised by different pharmacokinetic and pharmacodynamic properties compared to insulin glargine $100 \mathrm{U} / \mathrm{mL}$ (Gla-100), a first-generation basal insulin analogue commonly used in type 2 diabetes, and insulin detemir [7-9].

Second-generation basal insulins have a comparatively longer duration of action $(>24 \mathrm{~h}$ ), less glycaemic fluctuation (more even $24 \mathrm{~h}$ distribution) and less intrapatient and interpatient variability [10]. These pharmacological differences have important implications for practice.

\section{Supportive Clinical Trial Evidence}

A comprehensive collection of clinical trials comparing Gla-300 to current insulins, oral hypoglycaemic agents and in a variety of populations has been done [11-14] (EDITION studies). These are multinational trials with a range of patient populations. The 'average' patient was aged $57-60$ years, $52-57 \%$ being male with an HbA1c of 8.1-8.6\%.

EDITION 1, 2 and 3 demonstrated lower rates of hypoglycaemic events and particularly nocturnal hypoglycaemia, positively comparing Gla-300 to Gla-100 [12, 14]. EDITION 4 demonstrated comparable HbA1c levels between the two insulins but the eventual insulin Gla-300 dose was $0.62 \mathrm{U} / \mathrm{kg} /$ day compared to $0.53 \mathrm{U} / \mathrm{kg} /$ day for Gla-100 [13].

An independent meta-analysis comparing the EDITION and the BEGIN programmes involving degludec (IDeg) [15] suggested that, despite reductions in fasting plasma glucose (FPG), IDeg was associated with less improvement in HbA1c versus Gla-100 with a hypoglycaemia benefit only evident at night. Gla-300 showed similar HbA1c reduction to Gla-100 with lower risk of hypoglycaemia both at night and any time of the day.

Similarly, in a review of randomized controlled trials (RCTs) with Gla-300 and IDeg in patients with both type 1 and 2 diabetes [16], the study showed that a large number of patients succeeded in meeting HbA1c targets 
but also had less hypoglycaemic events with both insulins versus first-generation insulin glargine $100 \mathrm{U} / \mathrm{mL}$.

\section{Clinical Implications}

Second-generation basal insulin analogues such as Gla-300 and IDeg are at least as efficacious as first-generation basal insulin analogues in glycaemic control but have lower risk of hypoglycaemia (including nocturnal hypoglycaemia). Because of the longer insulin action beyond $24 \mathrm{~h}$, they are also very suitable for patients who have irregular meal patterns, shift workers, frequent travellers travelling across multiple time zones and the forgetful patient.

\section{UTILISING SECOND-GENERATION INSULIN GLARGINE $300 \mathrm{U} / \mathrm{ML}$ INSULIN IN CLINICAL PRACTICE}

\section{Case Vignette 1: Commencing Insulin and Titrating}

John is a 58-year-old male non-smoker with a body mass index (BMI) of 32 and diagnosed with type 2 diabetes for 10 years. He is employed at a refinery and does night shifts every 3 weeks.

He has evidence of early peripheral neuropathy and an estimated glomerular filtration rate (eGFR) of $70 \mathrm{~mL} / \mathrm{min} / 1.73 \mathrm{~m}^{2}$ without microalbuminuria, and no other microvascular or macrovascular complications. Despite good adherence to diet and exercise programs and treatment with maximum tolerated doses of metformin, gliclazide and sitagliptin, his HbA1c has been consistently increasing over the past 9 months and is now $77 \mathrm{mmol} / \mathrm{mol}(9.2 \%)$.

\section{Case Comment}

Adequate glycaemic control is important to prevent the onset of further microvascular complications in a person who needs to live a healthy life with many years ahead living with diabetes. Thus, his individualised target HbA1c is $\leq 53 \mathrm{mmol} / \mathrm{mol}(7 \%)$ if possible, without raising risks of hypoglycaemia. When considering the available therapies, to achieve target HbA1c without added oral tablet burden, and efficacy, insulin remains the glycaemic lowering therapy that is flexible, and efficacious to assist John in achieving his target. He would be an ideal candidate for a second-generation analogue such as insulin glargine $300 \mathrm{U} / \mathrm{mL}$ owing to the longer duration of action and because it can be taken at any time each day to suit his shift work. European and American Guidelines suggest that additional oral medication would not be a usual choice because of the level of his hyperglycaemia [17]. Initiating second-generation basal insulin analogues with his existing oral glucose-lowering therapies provides an opportunity to reduce delays in achieving effective glycaemic control (i.e. clinical inertia) $[18,19]$. The Bright study revealed that using Gla-300 could achieve adequate glycaemic control compared to IDeg with lower rates of hypoglycaemia [18]. Adding a Gla-300 to existing oral regimes may also offset the need for escalating doses of insulin. Alternatives could be a long-acting glucagon-like peptide 1 (GLP-1) receptor agonists but rationalisation of existing therapies would need to be hastened (ceasing the dipeptidyl peptidase 4 inhibitor [DPP4i] at initiation), potentially destabilising glycaemic control at this vital stage of upgrading glycaemic management. Also, GLP-1 agents lack the greater flexibility to titrate doses to glycaemic effect compared to insulin. As John has no established cardiac disease, the imperative to use agents that have been shown to benefit patients with established cardiovascular disease, such as a sodium/glucose cotransporter 2 inhibitor (SGLT2i) and liraglutide or dulaglutide (GLP-1 receptor agonists), may not be a priority.

\section{Initiation of Basal Insulin}

In insulin-naive patients, the recommendation is to commence a single daily insulin dose of Gla-300, commencing with 0.2 units $/ \mathrm{kg}=18$ units] The titration goal is to achieve a morning 


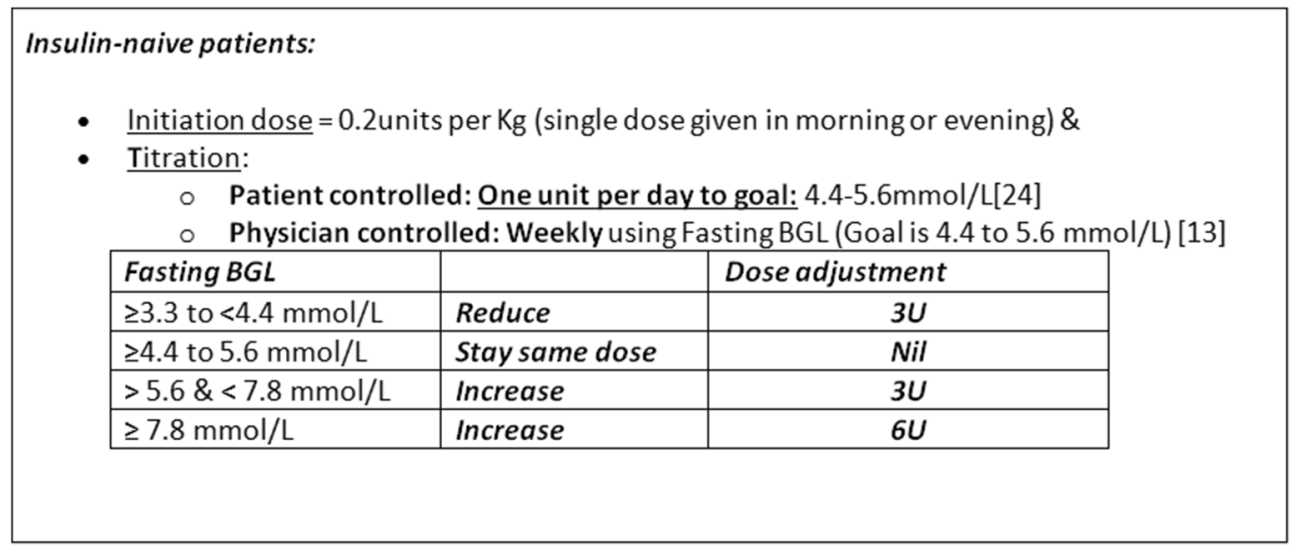

Fig. 1 Commencing insulin glargine $300 \mathrm{U} / \mathrm{mL}\left(\right.$ Toujeo $^{\circledR}$ )

fasting glucose between 4 and $7 \mathrm{mmol} / \mathrm{L} \mathrm{[20].}$ John was instructed in self-monitoring of his glucose plus hypoglycaemia management and asked to increase his dose as per Fig. 1, until he achieves his target fasting glucose without symptomatic or measurable hypoglycaemia.

Once John is close to achieving his fasting glucose goal and HbA1c, consideration should be given to reviewing existing oral therapies (see Fig. 3). His sulphonylurea (gliclazide) could be ceased to reduce the risk of hypoglycaemia but this must be matched by insulin dose titration to prevent further hyperglycaemia. If a replacement treatment is required consideration could be given to adding an agent to his metformin such as an SGLT2i. Alternatively, consideration could be given to gradually ceasing both his DPP4i (sitagliptin) and sulphonylurea (gliclazide) and introducing a GLP-1 receptor agonist such as short-acting exenatide to address his postprandial hyperglycaemia which may offer similar advantages but at the inconvenience of additional daily injections [21].

\section{Case Vignette 2: Switching Between Insulin Regimes}

Mary is a 64-year-old non-smoker who has had type 2 diabetes for 16 years. She is on a pre-mix (NovoMix $30^{\circledR}$ ) insulin at 40 units with her main meal and 48 units with her evening meal, as well as metformin $2 \mathrm{~g} /$ day, and empagliflozin $25 \mathrm{mg} /$ day. Since commencing insulin she has gained about $6 \%$ of her body weight and now weighs $102 \mathrm{~kg}$. She has atherosclerotic cardiovascular disease (ASCVD), chronic kidney disease $(\mathrm{CKD})$ stage $3 \mathrm{a} \quad(\mathrm{eGFR}=52)$, peripheral neuropathy and moderate non-proliferative diabetic retinopathy. She is troubled by frequent episodes of hypoglycaemia measured by flash glucose monitoring, especially overnight, and is becoming concerned as she lives alone. Her HbA1c $(66 \mathrm{mmol} / \mathrm{mol} ; 8.2 \%)$ is still not at her agreed target of $58 \mathrm{mmol} / \mathrm{mol}(7.5 \%)$.

\section{Case Comment}

In patients who are on insulin therapy and experiencing hypoglycaemic episodes, switching to a second-generation basal insulin analogue is an option. Continuous glucose monitoring (CGM) can be used to detect hidden hypoglycaemic episodes [22, 23]. Switching to a second-generation basal insulin analogue is a logical choice e.g. for the elderly, those living alone, those with inadequate glucose control requiring intensification or in patients having difficulties maintaining a strict 24-h dosing schedule.

Hypoglycaemia is a major risk factor for Mary and the risk could be considerably reduced by switching her to a second-gener- 
ation basal insulin analogue plus a short-acting insulin if required (basal plus) or basal insulin with a GLP-1 receptor agonist. This reflects a flatter 24-h glycaemic lowering effect of the newer-generation insulin analogues [7-9].

When commencing glargine U300, the starting dose would be her total daily insulin less $\quad 30 \% \quad[(40$ units +48 units $=88$ units $)-$ $30 \%=58$ units] (see Fig. 2). This could be introduced as a single morning or evening dose. Her Gla-300 will be titrated against her fasting blood glucose level (BGL).

Once her morning fasting blood glucose is near $6 \mathrm{mmol} / \mathrm{L}$, and there is no evidence of hypoglycaemia, we can focus on closely monitoring her postprandial blood glucose. If there is significant postprandial BGL excursions (see
Fig. 3), consideration could be given to the introduction of a GLP-1 receptor agonist with proven cardiovascular benefits, to assist with controlling the postprandial glucose and help her reduce weight without a significant increased risk of hypoglycaemia or introducing short-acting insulin, initially to those meals showing the greatest postprandial BGL excursions (basal plus) where a GLP-1 receptor agonist may not be efficacious enough to control significant postprandial hyperglycaemia (see Fig. 4).

\section{SUMMARY PRACTICE POINTS}

See Figs. 2, 3 and 4.

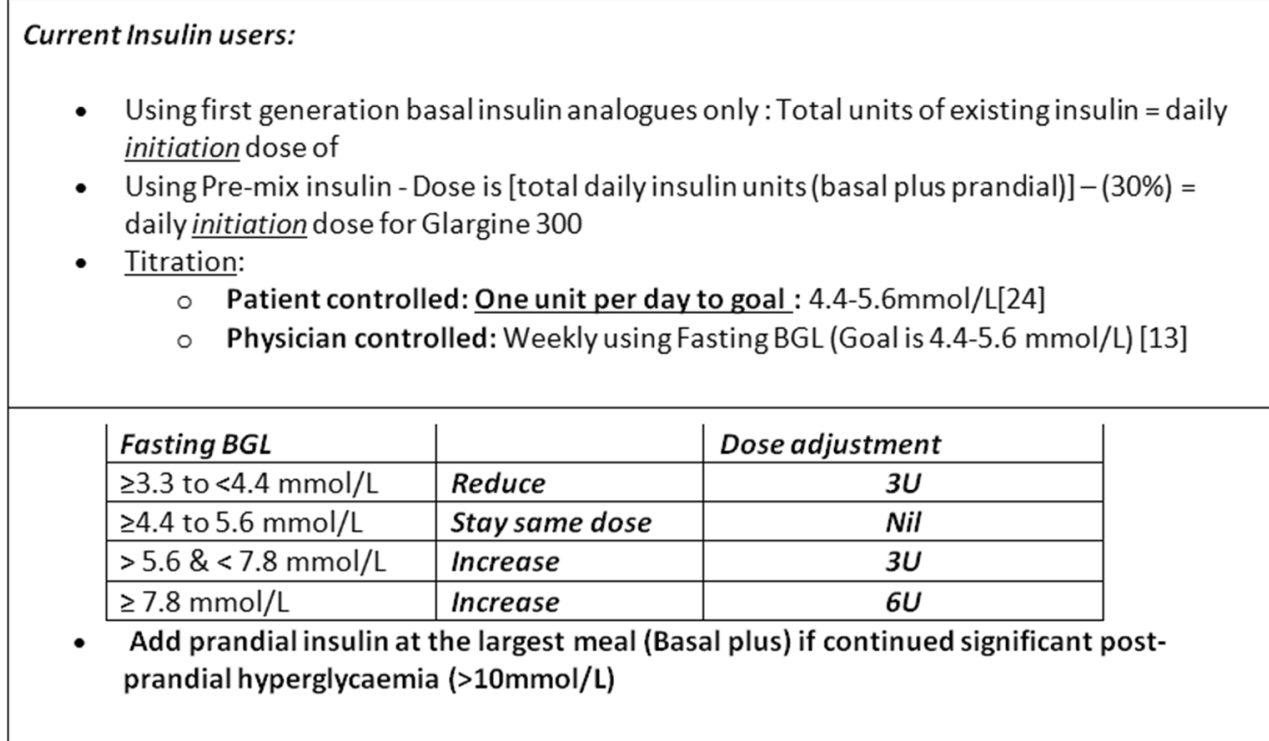

Fig. 2 Switching to insulin glargine $300 \mathrm{U} / \mathrm{mL}$ (Toujeo ${ }^{\circledR}$ ) 
- Metformin should be maintained

- Therapy targeting post-prandial glycaemia is synergistic with basal insulin

- Choices include oral agents: DPP4i, SGLT2i, or injectable: short acting GLP-1 receptor agonist.

- Secretagogues (e.g. sulphonylureas) may need review as titration reaches $\mathrm{HbA1ctarget}$

Fig. 3 Rationalising existing therapy

- Education of the patient on insulin administration, safety, supply and storage of pens (use a diabetes educator)

- Troubleshoot: Pen needle length (ideal 4-5-6mm), lipodystrophy (rare), driving, travel advice and sick day management

- When to seek specialist input (when things may go wrong)

- Failure to respond to titrating doses of insulin

- Complex multi-morbidity such as advancing CKD 4 or 5

- Polypharmacy that increases risks of insulin initiation and titration (hypoglycaemic risks etc)

- Driving licensing requirements

- Patient requests referral

Fig. 4 Additional clinical practice issues

\section{ACKNOWLEDGEMENTS}

Funding. This review and the journal's Rapid Service Fee were funded by Sanofi Australia.

Medical Writing Assistance. Minutes of the authors' meetings was provided by Mr. Tony James, an independent medical writer. Support for this assistance was funded by Sanofi Australia.

Authorship. All named authors meet the International Committee of Medical Journal Editors (ICMJE) criteria for authorship for this article, take responsibility for the integrity of the work as a whole, and have given their approval for this version to be published.

Disclosures. Gary Deed has received honoraria, speaker fees, consultancy fees, is a member of advisory boards or has appeared on expert panels for AstraZeneca, Boehringer Ingelheim, Bristol Myers Squibb, Inova, Lilly, Merck Sharp and Dohme, Novartis, Novo Nordisk, National Prescriber Service and Sanofi. Roy Rasalam has received honoraria, is a member of advisory boards or has appeared on expert panels for Lilly, Sanofi, AstraZeneca and Boehringer Ingelheim. Chee Khoo has previously received honoraria, travel sponsorship or consultancy payment from AstraZeneca, Sanofi and Novo Nordisk. Tom Dover has previously received honoraria, travel sponsorship, speaker fees, member of advisory boards or consultancy payment from AstraZeneca, Boehringer Ingelheim, Lilly, Merck Sharp and Dohme, Novartis, Novo Nordisk, Servier, Sanofi, Medtronic and Mylan. Nick Forgione has nothing to disclose.

Compliance with Ethics Guidelines. This article is based on previously conducted studies and does not contain any studies with human participants or animals performed by any of the authors.

Data Availability. Data sharing is not applicable to this article as no datasets were generated or analysed during the current study.

Open Access. This article is distributed under the terms of the Creative Commons Attribution-NonCommercial 4.0 International License (http://creativecommons.org/licenses/ by-nc/4.0/), which permits any 
noncommercial use, distribution, and reproduction in any medium, provided you give appropriate credit to the original author(s) and the source, provide a link to the Creative Commons license, and indicate if changes were made.

\section{REFERENCES}

1. International Diabetes Federation. IDF diabetes Atlas 8th edn. 2017;1-150.

2. Fonseca VA. Defining and characterizing the progression of type 2 diabetes. Diabetes Care. 2009;32(Suppl 2):S151-6.

3. Fulcher $G$, et al. What happens when patients require intensification from basal insulin? A retrospective audit of clinical practice for the treatment of type 2 diabetes from four Australian centres. Diabetes Res Clin Pract. 2015;108(3):405-13.

4. Carrington MJ, Cohen N, Wiley JF. Blood glucose levels and glycaemic burden in 76,341 patients attending primary care: bittersweet findings from a 9-year cohort study. Diabetes Res Clin Pract. 2017; 127:89-96.

5. Khunti K, Millar-Jones D. Clinical inertia to insulin initiation and intensification in the UK: a focused literature review. Primary Care Diabetes. 2017;11(1):3-12.

6. Idris I, et al. Associated factors that influenced persistence with basal analog insulin therapy among people with type 2 diabetes: an exploratory analysis from a UK real-world sample. Prim Care Diabetes. 2019;13(2):106-12.

7. Donner T, Sarkar S. Insulin-pharmacology, therapeutic regimens, and principles of intensive insulin therapy. In: Endotext, Feingold KR, Anawalt B, Boyce A, et al., editors. 2000, South Dartmouth: MDText.com.

8. Vargas-Uricoechea H. Efficacy and safety of insulin glargine $300 \mathrm{U} / \mathrm{mL}$ versus $100 \mathrm{U} / \mathrm{mL}$ in diabetes mellitus: a comprehensive review of the literature. J Diabetes Res. 2018;2018:2052101.

9. Stailey M, Conway SE. Review of the next generation of long-acting basal insulins: insulin degludec and insulin glargine. Consult Pharm. 2017;32(1):42-6.
10. Becker RH, et al. Low within- and between-day variability in exposure to new insulin glargine 300 U/mL. Diabetes Obes Metab. 2015;17(3):261-7.

11. Ritzel R, et al. Patient-level meta-analysis of the EDITION 1, 2 and 3 studies: glycaemic control and hypoglycaemia with new insulin glargine $300 \mathrm{U} /$ mL versus glargine $100 \mathrm{U} / \mathrm{mL}$ in people with type 2 diabetes. Diabetes Obes Metab. 2015;17(9):859-67.

12. Yki-Jarvinen $\mathrm{H}$, et al. Glycaemic control and hypoglycaemia with new insulin glargine $300 \mathrm{U} /$ mL versus insulin glargine $100 \mathrm{U} / \mathrm{mL}$ in people with type 2 diabetes using basal insulin and oral antihyperglycaemic drugs: the EDITION 2 randomized 12-month trial including 6-month extension. Diabetes Obes Metab. 2015;17(12):1142-9.

13. Bolli GB, et al. New insulin glargine $300 \mathrm{U} / \mathrm{mL}$ compared with glargine $100 \mathrm{U} / \mathrm{mL}$ in insulin-naive people with type 2 diabetes on oral glucose-lowering drugs: a randomized controlled trial (EDITION 3). Diabetes Obes Metab. 2015;17(4):386-94.

14. Riddle MC, et al. New insulin glargine 300 units $/ \mathrm{mL}$ versus glargine 100 units/mL in people with type 2 diabetes using basal and mealtime insulin: glucose control and hypoglycemia in a 6-month randomized controlled trial (EDITION 1). Diabetes Care. 2014;37(10):2755-62.

15. Roussel R, et al. Clinical perspectives from the BEGIN and EDITION programmes: trial-level metaanalyses outcomes with either degludec or glargine $300 \mathrm{U} / \mathrm{mL}$ vs glargine $100 \mathrm{U} / \mathrm{mL}$ in T2DM. Diabetes Metab. 2018;44(5):402-9.

16. Woo VC. A review of the clinical efficacy and safety of insulin degludec and glargine $300 \mathrm{U} / \mathrm{mL}$ in the treatment of diabetes mellitus. Clin Ther. 2017;39(82):S12-33.

17. Davies MJ, D'Alessio DA, Fradkin J, et al. Management of hyperglycemia in type 2 diabetes, 2018. A consensus report by the American Diabetes Association (ADA) and the European Association for the Study of Diabetes (EASD). Diabetes Care. 2018;41(12):2669-2701.

18. Cheng AYY, et al. Similar glycemic control and less or comparable hypoglycemia with insulin glargine $300 \mathrm{U} / \mathrm{mL}$ (Gla-300) vs. degludec $100 \mathrm{U} / \mathrm{mL}$ (IDeg$100)$ in insulin-naïve T2DM on antihyperglycemic drugs \pm GLP-1 RAs-the BRIGHT randomized study. Diabetes. 2018;67(Supplement 1):301.

19. Davies MJ, et al. Management of hyperglycaemia in type 2 diabetes, 2018. A consensus report by the American Diabetes Association (ADA) and the European Association for the Study of Diabetes (EASD). Diabetologia. 2018;61(12):2461-98. 
20. Imran SA, et al. Targets for glycemic control. Can J Diabetes. 2018;42:S42-6.

21. Ghosh S, et al. Evidence-based recommendations for insulin intensification strategies after basal insulin in type 2 diabetes. Diabetes Metab Syndr Clin Res Rev. 2017;11:S507-21.

22. Ahn D, Pettus J, Edelman S. Unblinded CGM should replace blinded CGM in the clinical management of diabetes. J Diabetes Sci Technol. 2016;10(3):793-8.
23. Wright EE Jr, Gavin JR 3rd. Clinical use of professional continuous glucose monitoring. Diabetes Technol Ther. 2017;19(S2):S12-5.

24. Yale J-F, et al. TITRATION: a randomized study to assess 2 treatment algorithms with new insulin glargine 300 units/mL. Can J Diabetes. 2017;41(5):478-84. 